\title{
Perencanaan Instalasi Pengolahan Air Limbah (IPAL) Portable untuk Kegiatan Usaha Pencucian Mobil di Kota Surabaya
}

\author{
Dini Novitrianingsih dan Harmin Sulistiyaning Titah \\ Jurusan Teknik Lingkungan, Fakultas Teknik Sipil dan Perencanaan, Institut Teknologi Sepuluh Nopember (ITS) \\ Jl. Arief Rahman Hakim, Surabaya 60111 Indonesia \\ e-mail: harmin_st@its.ac.id
}

\begin{abstract}
Abstrak-Pencemaran lingkungan yang terjadi di Kota Surabaya tidak terlepas dari kegiatan industri salah satunya yaitu usaha pencucian mobil. Hal tersebut berdampak pada penurunan kualitas lingkungan dikarenakan usaha pencucian mobil belum memiliki IPAL untuk mengolah limbah yang dihasilkan. Sehingga masih banyaknya usaha pencucian mobil yang membuang air limbah pencucian mobil langsung ke badan air tanpa diolah terlebih dahulu. Sebagian besar usaha pencucian mobil menggunakan lahan sewa/kontrak sebagai lokasi usaha sehingga untuk menerapkan IPAL konvensional secara permanen tidak dapat direalisasikan. Selain karena keterbatasan lahan, kondisi tersebut juga disebabkan oleh mahalnya biaya investasi pembangunan IPAL konvensional secara permanen. Untuk mengatasi hal tersebut maka dibutuhkan perencanaan IPAL yang memiliki biaya investasi rendah dan bersifat portable yaitu dapat dipindahkan sewaktu-waktu apabila usaha pencucian mobil ini berpindah lokasi.

Perencanaan instalasi pengolahan air limbah portable ini menggunakan secondary treatment Aerobic Biofilter sebagai alternatif pengolahan. Tahap perencanaan dimulai dengan pengumpulan data primer dan sekunder, kemudian dilanjutkan dengan tinjauan pustaka, penghitungan dimensi unit IPAL portable, penggambaran engineering design, dan penghitungan Rencana Anggaran Biaya (RAB) serta dilakukan pembahasan untuk mendapatkan kesimpulan dan saran yang sesuai dengan tujuan dari adanya perencanaan ini.

Dimensi untuk masing-masing unit pre-treatment yang terdiri dari oil trap dan sumur pengumpul sebesar $1,3 \mathrm{~m} \times 0,6 \mathrm{~m} \times 1 \mathrm{~m}$ dan $1 \mathrm{~m} \times 1 \mathrm{~m} \times 1 \mathrm{~m}$. Sedangkan dimensi unit IPAL portable yang terdiri dari tangki septik, aerobik biofilter, dan bak penampung secara berturut-turut sebesar 1,7 m x 0,4 m x 1,2 m; $0,5 \mathrm{~m}$ x 0,4 m $x$ 1,2 m sebanyak 2 kompartemen; dan dimensi unit bak penampung yang diperoleh dari lahan IPAL portable yang tersisa sebesar 0,7 m x 0,4 m x 1,2 m. Anggaran biaya yang dibutuhkan untuk pembangunan unit pre-treatment sebesar $R p$ 1.590.000,00. Sedangkan untuk unit IPAL portable sebesar Rp 3.900.000,00.
\end{abstract}

Kata Kunci-Aerobic Biofilter, Engineering Design, IPAL, Portable, Usaha Pencucian Mobil.

\section{PENDAHULUAN}

$\mathrm{U}$ SAHA pencucian mobil merupakan usaha yang saat ini memiliki prospek yang tinggi di Indonesia. Seiring bertambahnya jumlah penduduk, kebutuhan akan kendaraan bermotor juga semakin bertambah. Jumlah kendaraan bermotor terutama mobil yang terus meningkat, memberikan peluang munculnya usaha pencucian mobil yang dianggap menguntungkan dan meningkatkan perekonomian masyarakat di kota-kota besar seperti Surabaya [1] karena tidak semua orang mempunyai waktu luang untuk mencuci kendaraannya berhubung kesibukan dan aktifitas sehari-hari.

Usaha pencucian mobil juga memberikan dampak buruk terhadap kualitas lingkungan dikarenakan 90\% usaha pencucian mobil di Surabaya belum memiliki Instalasi Pengolahan Air Limbah (IPAL) [2]. Air limbah yang dihasilkan dari proses pencucian mobil langsung dibuang ke badan air yang menyebabkan pencemaran badan air.

Limbah yang dihasilkan dari usaha pencucian mobil ini memiliki kadar COD dan surfaktan yang masing-masing sebesar $768 \mathrm{mg} / \mathrm{L}$ dan 25,32 mg/L [3]. Serta kadar BOD dan TSS masing masing sebesar $520 \mathrm{mg} / \mathrm{L}$ dan $308,5 \mathrm{mg} / \mathrm{L}$ [4]. Air limbah yang dibuang ke badan air harus memenuhi standar baku mutu lingkungan sesuai dengan Peraturan Gubernur Jawa Timur Nomor 72 Tahun 2013 tentang baku mutu limbah cair industri dan kegiatan usaha lainnya di Jawa Timur bahwa Kadar TSS dan BOD yang dibuang ke badar air tidak boleh melebihi $100 \mathrm{mg} / \mathrm{L}$ dan untuk kadar COD tidak boleh melebihi $250 \mathrm{mg} / \mathrm{L}$. Sedangkan untuk kadar surfaktan menurut Keputusan Menteri Lingkungan Hidup Nomor: Kep51/MENLH/10/1995 tidak boleh melebihi $5 \mathrm{mg} / \mathrm{L}$.

Upaya pengelolaan limbah cair usaha pencucian mobil belum bisa dilakukan secara optimal karena memerlukan lahan yang luas [5]. Kondisi tersebut disebabkan lokasi usaha pencucian mobil yang berdekatan dengan usaha lainnya. Kelebihan dari desain IPAL portable adalah meningkatkan efisiensi operasi dan biaya pembuatan IPAL portable lebih murah daripada secara IPAL permanen serta IPAL portable secara ekonomi dapat menekan biaya investasi hingga $30 \%$ [6]. Desain IPAL portable disesuaikan dengan aspek teknis dan biaya yang sesuai dengan baku mutu yang berlaku sehingga dapat diterapkan untuk usaha pencucian mobil di Kota Surabaya.

\section{METODE PERENCANAAN}

\section{A. Ide Studi}

Ide studi diperoleh dari kondisi eksisting usaha pencucian mobil X di Kota Surabaya. Kondisi eksisting pada usaha pencucian mobil $\mathrm{X}$ di Kota Surabaya belum sesuai dengan kondisi ideal yang telah ditetapkan pemerintah, dimana $90 \%$ 
usaha pencucian mobil tidak memiliki IPAL. Hal tersebut menyebabkan air limbah usaha pencucian mobil langsung dibuang ke badan air terdekat tanpa diolah terlebih dahulu yang mengakibatkan terjadinya pencemaran lingkungan. Sedangkan pada kondisi ideal berdasarkan UU No. 32 Tahun 2009 tentang Perlindungan dan Pengelolaan Lingkungan Hidup bahwa setiap usaha yang menghasilkan limbah diwajibkan untuk mengelola limbah yang dihasilkan.

\section{B. Ruang Lingkup}

Ruang lingkup yang digunakan pada perencanaan desain IPAL Portable adalah sebagai berikut:

1. Lokasi pelaksanaan perencanaan berada di salah satu usaha pencucian mobil X di Surabaya.

2. Data yang diperlukan dalam perencanaan adalah penggunaan air bersih yang diperoleh dari rekening air bersih dan perhitungan air limbah yang diperoleh berdasarkan rekening air bersih.

3. Sampel dan karakteristik air limbah diperoleh dari salah satu kegiatan usaha pencucian mobil X di Kota Surabaya.

4. Parameter yang digunakan yaitu parameter kualitas air yang terdiri dari COD, BOD, TSS, pH, dan surfaktan.

5. Baku mutu limbah cair untuk BOD, COD, TSS, dan $\mathrm{pH}$ mengacu pada Peraturan Gubernur Jawa Timur Nomor 72 Tahun 2013 mengenai Baku Mutu Limbah Cair Industri dan Kegiatan Usaha Lainnya di Jawa Timur. Sedangkan untuk surfaktan mengacu pada Keputusan Menteri Lingkungan Hidup Nomor: Kep51/MENLH/10/1995.

6. Perhitungan Rencana Anggaran Biaya yang disesuaikan dengan Harga Satuan Pokok Kegiatan (HSPK) Kota Surabaya.

\section{Pengumpulan Data}

Data yang digunakan dalam perencanaan IPAL Portable pada usaha pencucian mobil $X$ di Kota Surabaya yaitu data primer dan data sekunder. Data primer diperoleh dari survei lapangan dan uji laboratorium karakteristik air limbah yang terdiri dari nilai COD, BOD, TSS, pH, dan surfaktan. Sedangkan data sekunder diperoleh dari data penggunaan air bersih yang dilihat dari rekening meter air bersih, harga satuan pekerjaan konstruksi di Kota Surabaya, dan lokasi serta kelas badan air penerima.

\section{HASIL PERENCANAAN}

\section{A. Penentuan Debit Air Limbah Pencucian Mobil}

Penentuan debit air limbah diperoleh melalui penggunaan meter rekening air bersih bulanan pada usaha pencucian mobil $\mathrm{X}$ di Surabaya. Jam operasional pada usaha pencucian mobil X yaitu 15 jam. Terhitung mulai pukul 07.00 WIB - 22.00 WIB. Debit air limbah $=180 \mathrm{~m}^{3} /$ bulan.

$$
\begin{aligned}
& =6 \mathrm{~m}^{3} / \text { hari. } \\
& =0,4 \mathrm{~m}^{3} / \mathrm{jam} .
\end{aligned}
$$

\section{B. Karakteristik Air Limbah}

Karakteristik air limbah pencucian mobil yang digunakan terdiri dari 4 parameter antara lain TSS, COD, BOD, pH, dan surfaktan. Hasil rata-rata uji parameter kualitas air limbah pencucian mobil X di Kota Surabaya sebanyak 2 kali selama 2 minggu berturut-turut untuk TSS sebesar $363 \mathrm{mg} / \mathrm{L}$, COD sebesar $190 \mathrm{mg} / \mathrm{L}$, BOD sebesar $114 \mathrm{mg} / \mathrm{L}$, pH sebesar 7,35, dan surfaktan sebesar 11,93 mg/L.

\section{Unit Pengolahan yang Digunakan}

Unit pengolahan yang digunakan dalam perencanaan ini yaitu diawali dengan unit pre-treatment yang terdiri dari oil trap dan sumur pengumpul kemudian dilakukan pengolahan lanjutan pada IPAL portable yang terdiri dari unit tangki septik, aerobik filter dan bak penampung. Unit pre-tratment merupakan unit opsional jika usaha pencucian mobil yang akan membangun IPAL portable belum memiliki unit pretreatment sebelumnya.

a. Hasil perhitungan engineering design unit pre-treatment dapat dilihat sebagai berikut:

- Oil Trap:

Qave $\quad=6 \mathrm{~m}^{3} / \mathrm{hari}=0,4 \mathrm{~m}^{3} / \mathrm{jam}$

Td $=2$ jam

$\mathrm{H}$ rencana $\quad=1 \mathrm{~m}$

Vol. Bak $=0,8 \mathrm{~m}^{3}$

Panjang $\quad=1,3 \mathrm{~m}$

Lebar $\quad=0,6 \mathrm{~m}$

- Sumur Pengumpul:

Qave $\quad=0,000111 \mathrm{~m}^{3} /$ detik

$\mathrm{Td}=5$ menit $=300 \operatorname{detik}(5-10$ menit $)$

$\mathrm{H}$ rencana $\quad=1 \mathrm{~m}$

Vol. Bak $=0,033333 \mathrm{~m}^{2}$

Panjang $\quad=1 \mathrm{~m}$

Lebar $\quad=1 \mathrm{~m}$

Head Pompa $=3,5572 \mathrm{~m}$ (pompa yang digunakan dalam perencanaan ini yaitu pompa celup (submersible) otomatis Aldo 207 dengan spesifikasi daya listrik: 200 watt, kedalaman celup: 6 meter, daya dorong: maksimal 6 meter, kapasitas air: maksimal 6000 liter/hari, otomatis: ya, diameter pipa keluar: $1 "-1 / 2$ ", voltage $220 \mathrm{~V}-50 \mathrm{~Hz}$ ).

b. Hasil perhitungan engineering design unit IPAL portable dapat dilihat sebagai berikut:

- Tangki Septik:

Qave $\quad=6 \mathrm{~m}^{3} / \mathrm{hari}=0,4 \mathrm{~m}^{3} / \mathrm{jam}$

$\mathrm{Td}=2 \mathrm{jam}(2-4 \mathrm{jam})$

$\mathrm{H}$ rencana $=1,2 \mathrm{~m}$

Vol. Bak $=0,8 \mathrm{~m}^{3}$

Panjang $\quad=1,7 \mathrm{~m}$

Lebar $=0,4 \mathrm{~m}$

- Aerobik Biofilter:

-Kriteria Desain:

Organic Loading Rate $=5-6 \mathrm{~kg} \mathrm{COD} / \mathrm{m}^{3}$.hari

HRT di tangki septik $=2$ jam

HRT di aerobik biofilter $=10-40$ jam

HLR $\quad=1 \mathrm{~m}^{3} / \mathrm{m}^{2} . j \mathrm{jam}\left(<2 \mathrm{~m}^{3} / \mathrm{m}^{2} . \mathrm{jam}\right)$

Perhitungan:

Qave $\quad=6 \mathrm{~m}^{3} / \mathrm{hari}=0,4 \mathrm{~m}^{3} / \mathrm{jam}=400 \mathrm{~L} / \mathrm{jam}$

$\mathrm{Td} \quad=18 \mathrm{jam}$

Porositas media $=98 \%$ (media filter sarang tawon)

$\mathrm{H}$ rencana $\quad=1,2 \mathrm{~m}$

Vol. Media $\quad=0,05 \mathrm{~m}^{3}$

Vol. Rongga $=0,49 \mathrm{~m}^{3}$ 
Tinggi per media $=0,5 \mathrm{~m}(2$ kompartemen $)$

$$
\begin{array}{ll}
\text { Panjang } & =0,5 \mathrm{~m} \\
\text { Lebar } & =0,4 \mathrm{~m} \\
\text { Vup flow } & =2 \mathrm{~m} / \mathrm{jam}(\leq 2 \mathrm{~m} / \mathrm{jam}, \text { memenuhi })
\end{array}
$$

Kebutuhan udara aerobik biofilter per kompartemen yaitu 0,27 $\mathrm{m}^{3} /$ menit. Blower yang dibutuhkan yaitu blower dengan kapasitas minimal setara atau lebih besar dari jumlah kebutuhan udara per kompartemen. Sehingga blower yang sesuai pada perencanaan kali ini yaitu blower dengan tipe GF180 merk Resun Air Blower dengan kapasitas suplai udara sebesar $0,3 \mathrm{~m}^{3} /$ menit, power: 370 watt, pressure: $0,160 \mathrm{Mpa}$, output: $37200 \mathrm{~L} / \mathrm{jam}$, berat blower: $12 \mathrm{~kg}$, dimensi: 220x250x260 mm.

- Bak Penampung:

Qave $\quad=6 \mathrm{~m}^{3} / \mathrm{hari}=0,4 \mathrm{~m}^{3} / \mathrm{jam}$

$\mathrm{Td}=0,5 \mathrm{jam}=30$ menit (tidak lebih dari 10 menit)

$\mathrm{H}$ rencana $\quad=1,2 \mathrm{~m}$

Panjang $\quad=0,7 \mathrm{~m}$ (menyesuaikan dengan lahan IPAL portable yang tersisa)

Lebar $\quad=0,4 \mathrm{~m}$ (menyesuaikan dengan lahan IPAL portable yang tersisa)

c. Pipa Influen dan Efluen Unit Pre-Treatment dan Unit IPAL Portable

Pada perencanaan ini debit air limbah pencucian mobil yang masuk sama dengan debit yang keluar yaitu $0,4 \mathrm{~m}^{3} / \mathrm{jam}$ dengan kecepatan $0,3 \mathrm{~m} /$ detik. Sehingga diameter pipa influen dan efluen memiliki diameter yang sama. Pipa yang digunakan dalam perencanaan ini yaitu pipa AW dikarenakan memiliki ukuran diameter terkecil yang dijual di pasaran yaitu sebesar $22 \mathrm{~mm}$.

\section{Luas Lahan IPAL Portable}

Unit aerobik biofilter disusun secara paralel dengan tujuan untuk penghematan lahan, namun arah aliran dalam unit aerobik biolfilter tetep menggunakan sistem seri dan upflow. Berikut perhitungan luas lahan IPAL portable:

$\begin{array}{ll}\text { Panjang aerobik biofilter } & =1 \mathrm{~m} \text { (termasuk } 2 \text { tempat } \\ & =0,4 \mathrm{~m} \\ \text { Lebar bangunan } & =1,7 \mathrm{~m} \\ \text { Panjang tangki septik } & =1,7 \mathrm{~m} \\ \text { Panjang total IPAL Portable } & =0,8 \mathrm{~m} \\ \text { L total IPAL portable } & =1,36 \mathrm{~m}^{2} \\ \text { A IPAL portable } & \end{array}$

Denah bangunan IPAL Portable dapat dilihat pada Gambar 1. Potongan memanjang (A-A dan C-C) IPAL Portable dapat dilihat pada gambar 2. Sedangkan potongan melintang (B-B dan D-D) IPAL Portable dapat dilihat pada gambar 3.

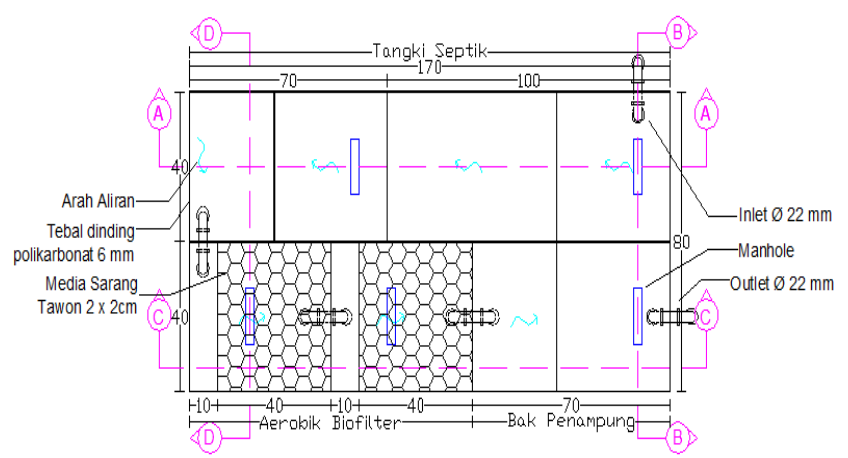

Gambar 1. Denah IPAL Portable
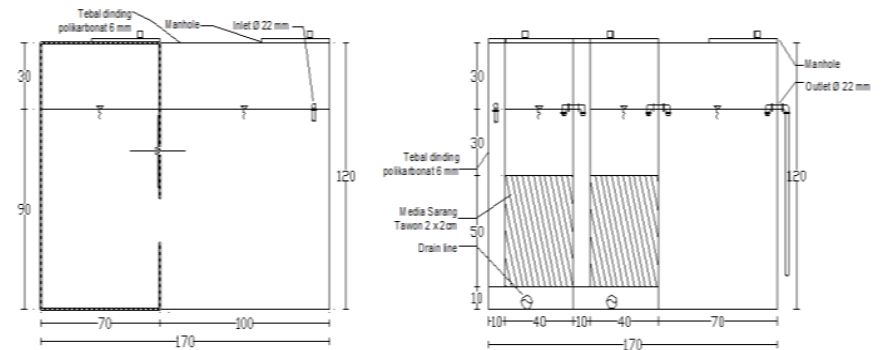

Gambar 2. Potongan Memanjang A-A (a) dan Potongan Memanjang C-C (b) IPAL Portable

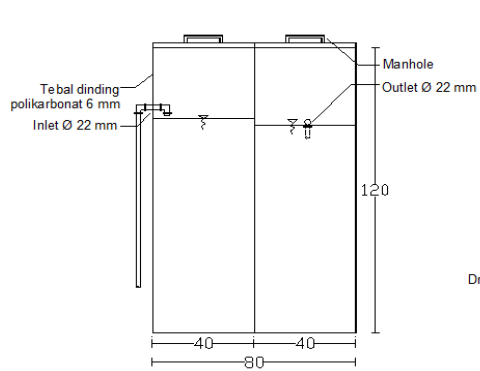

(c)

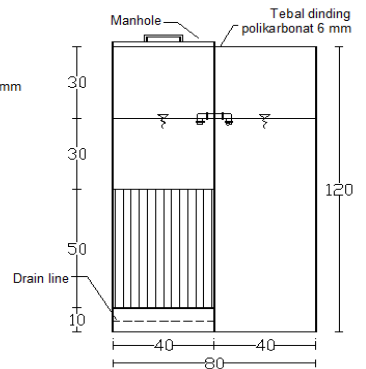

(d)
Gambar 3. Potongan Melintang B-B (c) dan Potongan Melintang D-D (d) IPAL Portable

\section{E. Kesetimbangan Massa}

Kesetimbangan massa digunakan untuk menentukan arah dan besaran energi yang terbebaskan akibat proses pengolahan air limbah pencucian mobil dengan menggunakan IPAL portable. Berikut diagram alir dari kesetimbangan massa IPAL portable:

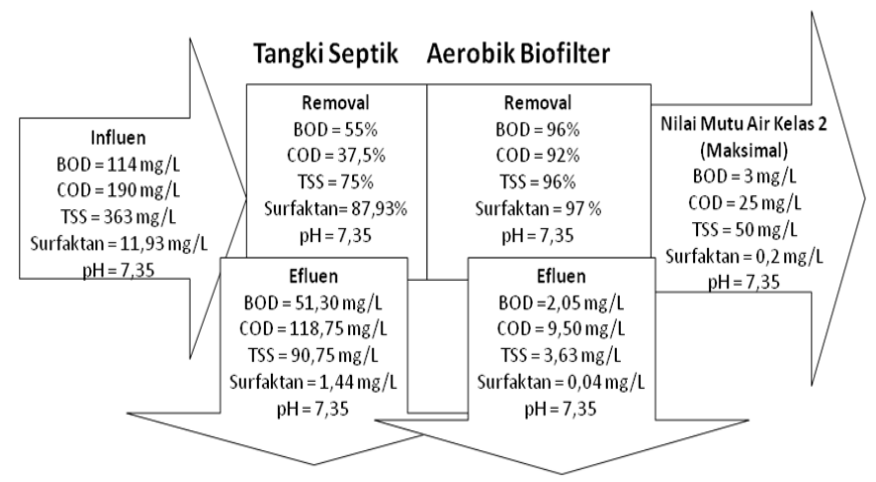

Gambar 4. Diagram Alir Kesetimbangan Massa IPAL Portable

Gambar diatas menunjukkan bahwa air limbah hasil pencucian mobil X di Kota Surabaya telah memenuhi baku 
mutu yang ditetapkan pemerintah sesuai dengan Pergub. Jawa Timur No. 72 Tahun 2013 untuk parameter BOD, COD, TSS, dan $\mathrm{pH}$. Sedangkan untuk parameter surfaktan didasarkan pada Keputusan Menteri Lingkungan Hidup Nomor: Kep51/MENLH/10/1995. Baku mutu untuk BOD dan TSS 100 $\mathrm{mg} / \mathrm{L}, \mathrm{COD} 250 \mathrm{mg} / \mathrm{L}$, pH 6-9, dan surfaktan $5 \mathrm{mg} / \mathrm{L}$. Hasil akhir yang diperoleh dari pengolahan IPAL portable yang kemudian ditampung dengan bak penampung tersebut dapat memenuhi nilai mutu air kelas 2 berdasarkan PP No. 82 Tahun 2001 yang peruntukkannya digunakan untuk prasarana/sarana rekreasi air, pembudidayaan ikan air tawar, peternakan ,air untuk mengairi pertanaman, dan atau peruntukkan lain yang mempersyaratkan mutu air yang sama dengan kegunaan tersebut.

\section{RANCANGAN ANGGARAN BIAYA}

Rencana anggaran biaya (RAB) pada perencanaan ini didasarkan pada Harga Satuan Pokok Kegiatan (HSPK) Kota Surabaya 2015. Dari nilai HSPK tersebut maka dapat diketahui total biaya yang dibutuhkan tiap pekerjaannya. Perhitungan RAB dibagi menjadi 2 yaitu perhitungan $\mathrm{RAB}$ unit pre-tratment dapat dilihat pada Tabel 1 dan perhitungan RAB unit IPAL portable dapat dilihat pada Tabel 2.

Tabel 1.

Rencana Anggaran Biaya Unit Pre-Treatment

\begin{tabular}{|c|c|c|c|c|c|}
\hline NO. & URAIAN PEKERJAAN & SAT & VOL & $\begin{array}{c}\text { HARGA } \\
\text { SATUAN } \\
\text { (dalam Rp) }\end{array}$ & $\frac{\text { HARGA }}{\text { (dalam Rp) }}$ \\
\hline $\mathrm{I}$ & \multicolumn{5}{|c|}{$\begin{array}{l}\mid \\
\text { PEKERJAAN PERSIAPAN } \\
\text { (dalam Rp) }\end{array}$} \\
\hline 1 & $\begin{array}{l}\text { PEK. PEMBERSIHAN } \\
\text { LAPANGAN RINGAN DAN } \\
\text { PERATAAN }\end{array}$ & $\mathrm{m}^{2}$ & 1,8 & Rp 7.950 & Rp $\quad 14.310$ \\
\hline 2 & $\begin{array}{l}\text { PENGGALIANTANAH } \\
\text { BIASA UNTUK } \\
\text { KONSTRUKSI } \\
\end{array}$ & $\mathrm{m}^{3}$ & 1,8 & Rp 77.250 & Rp $\quad 139.050$ \\
\hline II & \multicolumn{5}{|c|}{$\begin{array}{r}\text { SUB TOTALI } \\
\text { PEKERJAAN UTAMA }\end{array}$} \\
\hline & $\begin{array}{l}\text { PEK. PEMASANGAN } \\
\text { POLIKARBONAT }\end{array}$ & $\mathrm{m}^{3}$ & 1,38 & Rp 350.000 & Rp $\quad 483.000$ \\
\hline 1 & $\begin{array}{l}\text { PEK. PEMASANGAN PIPA } \\
\text { SOCKET }\end{array}$ & buah & 3 & Rp $\quad 1.880$ & 5.640 \\
\hline 2 & PEK. PEMASANGAN PIPA & $\mathrm{m}$ & 2,85 & Rp $\quad 6.685$ & $\begin{array}{ll}\mathrm{Rp} & 19.052\end{array}$ \\
\hline 3 & $\begin{array}{l}\text { PEK. PEMASANGAN PIPA } \\
\text { ELBOW }\end{array}$ & buah & 6 & Rp $\quad 2.515$ & 15.090 \\
\hline 4 & $\begin{array}{l}\text { PEK. PEMASANGAN } \\
\text { POMPA }\end{array}$ & buah & 1 & Rp 855.600 & Rp 855.600 \\
\hline III & \multicolumn{5}{|c|}{ SUB TOTAL II } \\
\hline 1 & $\begin{array}{l}\text { PEK. PENGURUGAN } \\
\text { TANAH KEMBALI UNTUK } \\
\text { KONSTRUKSI }\end{array}$ & $\mathrm{m}^{3}$ & 1,8 & Rp 13.983 & Rp $\quad 25.169$ \\
\hline 2 & $\begin{array}{l}\text { PEK. PEMBERSIHAN } \\
\text { LAPANGANDAN } \\
\text { PERATAAN TANAH }\end{array}$ & $\mathrm{m}^{2}$ & 1,8 & 670 & Rp $\quad 30.006$ \\
\hline & TOTAL & & & & $\begin{array}{lr}\operatorname{Rp} & 55.175 \\
\operatorname{Rp} 1.586 .917\end{array}$ \\
\hline
\end{tabular}

Tabel 2.

Rekapitulasi BOQ dan RAB Unit Pre-Treatment

\begin{tabular}{|c|l|c|}
\hline \multirow{2}{*}{ NO. } & \multicolumn{1}{|c|}{ URAIAN PEKERJAAN } & \multicolumn{2}{|c|}{$\begin{array}{c}\text { HARGA } \\
\text { (dalam Rp) }\end{array}$} \\
\hline 1 & PEKERJAAN PERSIAPAN & $\mathrm{Rp} 153.360$ \\
\hline 2 & PEKERJAAN PIPA & $\mathrm{Rp} 1.378 .382$ \\
\hline 3 & FINISHING & $\mathrm{Rp} 55.175$ \\
\hline \hline & SUB TOTAL = I s/d III & $\mathrm{Rp} 1.586 .917$ \\
\hline \hline \multicolumn{2}{|c|}{ PEMBULATAN } & $\mathrm{Rp} 1.590 .000$ \\
\hline
\end{tabular}

Tabel 3.

Rencana Anggaran Biaya Unit IPAL Portable

\begin{tabular}{|c|c|c|c|c|c|}
\hline NO. & URAIAN PEKERJAAN & SAT & VOL & $\begin{array}{c}\text { HARGA } \\
\text { SATUAN } \\
\text { (dalam Rp) } \\
\end{array}$ & $\begin{array}{c}\text { HARGA } \\
\text { (dalam Rp) }\end{array}$ \\
\hline 1 & & \multicolumn{4}{|c|}{ PEKERJAAN PERSIAPAN } \\
\hline 2 & $\begin{array}{l}\text { PEK. PEMASANGAN } \\
\text { BESIRANGKAIPAL }\end{array}$ & $\mathrm{m}^{2}$ & 1,36 & $\operatorname{Rp} 75.387$ & Rp 102.526 \\
\hline 3 & $\begin{array}{l}\text { PEK. PERAKITAN BESI } \\
\text { RANGKAIPAL }\end{array}$ & $\mathrm{m}^{2}$ & 1,36 & 501 & $\mathrm{Rp}$ \\
\hline 4 & $\begin{array}{l}\text { PEK. PENGELASAN BESI } \\
\text { RANGKA IPAL }\end{array}$ & $\mathrm{m}^{2}$ & 1,36 & Rp & Rp \\
\hline 5 & $\begin{array}{l}\text { PEK. PEMASANGAN } \\
\text { RANGKA RODA }\end{array}$ & buah & 1 & Rp1.660.234 & Rp 1.660.234 \\
\hline$\pi$ & \multicolumn{5}{|c|}{$\begin{array}{c}\text { SUB TOTAL I } \\
\text { PEKERJAAN UTAMA }\end{array}$} \\
\hline 1 & $\begin{array}{l}\text { PEK. PEMASANGAN } \\
\text { POLIKARBONAT }\end{array}$ & $\mathrm{m}^{3}$ & 2,09 & Rp 350.000 & Rp 730.800 \\
\hline 2 & $\begin{array}{l}\text { PEK. PELUBBANGAN } \\
\text { DRAIN LINE }\end{array}$ & buah & 2 & 222 & Rp \\
\hline 3 & $\begin{array}{l}\text { PEK. PEMASANGAN } \\
\text { MEDIA SARANG TAWON }\end{array}$ & buah & 2 & Rp $\quad 66.700$ & Rp $\quad 133.400$ \\
\hline 4 & $\begin{array}{l}\text { PEK. PEMASANGAN } \\
\text { PIPA SOCKET }\end{array}$ & buah & 5 & Rp $\quad 1.880$ & 9.400 \\
\hline 5 & $\begin{array}{l}\text { PEK. PEMASANGAN } \\
\text { PIPA ELBOW }\end{array}$ & buah & 10 & 2.515 & Rp $\quad 25.150$ \\
\hline 6 & $\begin{array}{l}\text { PEK. PEMASANGAN } \\
\text { AKSESORIS DRAIN LINE }\end{array}$ & buah & 2 & $\begin{array}{rr}\mathrm{Rp} \quad 6.685 \\
\text { SUB TOTALIII }\end{array}$ & $\begin{array}{rr}R p & 13.370 \\
R p & 912.564\end{array}$ \\
\hline 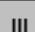 & \multicolumn{5}{|c|}{ FINISHING } \\
\hline 1 & $\begin{array}{l}\text { PEK. PEMASANGAN } \\
\text { PIPA }\end{array}$ & $\mathrm{m}$ & 2,64 & 6.685 & Rp $\quad 17.648$ \\
\hline 2 & $\begin{array}{l}\text { PEK. PEMASANGAN } \\
\text { BLOWER }\end{array}$ & buah & 1 & Rp 1.205 .600 & Rp 1.205 .600 \\
\hline & & & & $\frac{\text { SUB TOTAL III }}{\text { TOTAL }}$ & $\begin{array}{l}\text { Rp 1.223.248 } \\
\text { Rp 3.899.649 }\end{array}$ \\
\hline
\end{tabular}

Tabel 4

Rekapitulasi BOQ dan RAB Unit Aerobik Biofilter

\begin{tabular}{|c|l|c|}
\hline NO. & \multicolumn{1}{|c|}{ URAIAN PEKERJAAN } & \multicolumn{2}{|c|}{$\begin{array}{c}\text { HARGA } \\
\text { (dalam Rp) }\end{array}$} \\
\hline 1 & PEKERJAAN PERSIAPAN & Rp 1.763 .837 \\
\hline 2 & PEKERJAAN PIPA & $R p 912.564$ \\
\hline 3 & FINISHING & $R p 1.223 .248$ \\
\hline \hline & SUB TOTAL $=$ I s/d III & $R p 3.899 .649$ \\
\hline \hline & PEMBULATAN & $R p 3.900 .000$ \\
\hline
\end{tabular}

Berdasarkan Tabel 2 biaya total yang dibutuhkan untuk pembangunan unit pre-treatment IPAL yaitu oil trap dan sumur pengumpul sebesar $\mathrm{Rp} 1.590 .000,00$. Namun, pembangunan pre-treatment adalah opsional jika usaha pencucian mobil yang akan membangun IPAL portable ini belum memiliki unit pre-treatment sebelumnya. Sedangkan Berdasarkan Tabel 4 biaya total yang dibutuhkan untuk pembangunan IPAL unit aerobik biofilter yaitu sebesar Rp 3.900.000,00.

\section{KESIMPULAN}

1. Dimensi masing-masing unit pre-treatment yang terdiri dari oil trap dan sumur pengumpul serta dimensi unit IPAL portable yang terdiri dari tangki septik, aerobik biofilter,dan bak penampung.

-Dimensi unit oil trap 1,3 m x 0,6 m x $1 \mathrm{~m}$.

-Dimensi unit sumur pengumpul $1 \mathrm{~m} \times 1 \mathrm{~m} \times 1 \mathrm{~m}$.

-Dimensi unit tangki septik 1,7 m x 0,4 m x 1,2 m.

-Dimensi unit aeobik biofilter 0,5 m x 0,4 m x 1,2 m sebanyak 2 kompartemen.

-Dimensi unit bak penampung yang diperoleh dari lahan IPAL portable yang tersisa $0,7 \mathrm{~m} \times 0,4 \mathrm{~m} \times 1,2 \mathrm{~m}$.

2. Anggaran biaya yang dibutuhkan untuk pembangunan unit pre-treatment sebesar Rp 1.590.000,00. Sedangkan untuk unit IPAL portable sebesar Rp 3.900.000,00. 


\section{DAFTAR PUSTAKA}

[1] Evy., Anis., dan Agusfian. 2013. Penurunan COD, TSS, dan Minyak Lemak pada Limbah Cair Pencucian Mobil dengan Unit Pengolahan Trickling Filter. Progdi Teknik Lingkungan, Fakultas Teknik Sipil dan Perencanaan, Institut Teknologi Nasional Malang.

[2] Musdiq. 2014. BLH Akan Sanksi Tempat Usaha yang Belum Miliki IPAL. Wawancara oleh Koran Nusantara Online dan ditulis Tanggal 18 Agustus 2016 pukul 16.18 WIB.

[3] Chrisafitri, A., dan Karnaningroem, N. 2012. Pengolahan Air Limbah Pencucian Mobil dengan Reaktor Saringan Pasir Lambat dan Karbon Aktif. Prosiding Seminar Nasional Manajemen Teknologi XVI, Surabaya.

[4] Yasin. S., Iqbal, T., Arshad, Z., Rustam, M., dan Zafar, M. 2012.Environmental Pollution From automobile Vehicle Service Stations. Journal of Quality and Technology Management, Volume VIII, Issue I, June 2012, Page $61-70$.

[5] Maharani, R. M., dan Damayanti, A. 2013. Pengolah Limbah Cair Rumah Makan Menggunakan Membran Nanofiltrasi Silika Aliran Cross Flow untuk Menurunkan Fosfat dan Amonium. Jurnal Teknik Pomits, Vol. 2. pp: 92-97.

[6] Ariani, N. M. 2011. Otomatisasi Instalasi Pengolahan Air Limbah (IPAL) Sistem Mobile di Baristand Industri Surabaya. Jurnal Riset Industri, Vol. 5, No. 2, pp: 183-194. 